\title{
Pemilihan Titik Knot Optimal Model Spline Truncated dalam Regresi Nonparametrik Multivariabel dengan GCV
}

\author{
Luh Putu Safitri Pratiwi \\ Program Studi Sistem Informasi, Institut Teknologi dan Bisnis Stikom Bali \\ e-mail: putu_safitri@stikom-bali.ac.id
}

\begin{abstract}
One of the most frequently studied nonparametric regression model approaches is the spline truncated. This method is applied to cases of Maternal Mortality Rate because in various cases there is an increase in maternal mortality problems so that the government is expected to be more serious in dealing with and suppressing the MMR value through the programs launched or by overcoming the factors that significantly influence the high MMR value. This study aims to examine the determination of the optimal knot point of the multivariable nonparametric spline regression model using the GCV method as the optimal knot point selection method. The criteria for selecting the best model in this study using the MSE value. The results obtained are the best model suitable for AKI 2017, namely by using the GCV method which is located in the three-knot linear spline, which is 0.07722, and an MSE value of 0.018. The variables that have affect the model are the percentage of deliveries performed with the help of medical personnel (xl), the percentage of pregnant women who receive Fel tablets $(x 2)$, the percentage of pregnant women implementing the $K 1(x 3)$, and the percentage of pregnant women implementing the K4 $(x 4)$
\end{abstract}

Keywords: GCV, Spline, Nonparametric, AKI, Knot

\begin{abstract}
Abstrak: Salah satu pendekatan model regresi nonparametrik yang paling sering dipelajari adalah spline truncated. Cara ini diterapkan pada kasus Angka Kematian Ibu karena pada berbagai kasus terjadi peningkatan masalah kematian ibu sehingga diharapkan pemerintah lebih serius dalam menangani dan menekan nilai AKI melalui program yang dicanangkan atau dengan mengatasi faktor-faktor yang ada. berpengaruh signifikan terhadap nilai MMR yang tinggi. Penelitian ini bertujuan untuk menguji penentuan titik simpul optimal model regresi multivariabel nonparametrik spline dengan menggunakan metode GCV sebagai metode pemilihan titik simpul optimal. Kriteria pemilihan model terbaik dalam penelitian ini menggunakan nilai MSE. Hasil yang diperoleh adalah model terbaik yang sesuai untuk AKI 2017 yaitu dengan menggunakan metode GCV yang terletak pada spline linier tiga simpul yaitu sebesar 0,07722, dan nilai MSE sebesar 0,018. Variabel yang berpengaruh terhadap model adalah persentase persalinan oleh tenaga medis (x1), persentase ibu hamil mengkonsumsi Tablet Fel (x2), persentase ibu hamil melakukan program $K 1$ (x3), persentase ibu hamil melakukan program $K 4(x 4)$
\end{abstract}

Kata Kunci: GCV, Spline, Nonparametrik, AKI, Knot 


\section{Pendahuluan}

Pendekatan regresi nonparametrik adalah prosedur statistik yang memiliki kelenturan terutama dalam penentuan bentuk kurvanya. Pendekatan regresi nonparametrik digunakan karena tidak terkait dengan asumsi bentuk kurva regresi seperti halnya pada regresi parametrik, dan lebih fleksibel. Berbeda halnya dengan statistik nonparametrik yang merupakan metode statistik yang dapat digunakan dengan mengabaikan segala asumsi, terutama yang berkaitan dengan distribusi normal.Pada tahun 2016, Budiantara mengemukakan metode Spline adalah salah satu model regresinonparametrik yang sangat popular dalam dasawarsa terakhir. Ada beberapa model regresi nonparametrik yang banyak digunakan diantaranya Spline (Budiantara, 2016), Kernel (Hu, Wang, \& Carrol, 2004), Estimator Deret Fourier (Amato, Antoniadis, dan De Feis, 2002), dan Polinomial Lokal (Fan \& Jiang, 2005).

Penentuan orde untuk membentuk model regresi, banyaknyaknya knot, dan lokasi penempatan knot merupakan beberapa kreteria yang harus diperhatikan untuk membentuk model regresi spline. Pada data sering terjadi pola umum sedangkan perubahan pola di daerah tertentu pada kurva disebut dengan banyaknya knot dan lokasi knot hal inilah yang menjadi dasar dalam penentuan orde pada model (Budiantara, Suryadi, Otok, \& Guritno, 2006). Knot merupakan titik perpaduan bersama dimana terdapat perubahan perilaku pola pada interval yang berlainan.

Budiantara (2006) menjelaskan keekuivalenan penggunaan basis fungsi keluarga Spline truncated dalam hal pemilihan titik knot optimal dan pemilihan parameter penghalus. GCV merupakan suatu metode yang populer digunakan untuk memilih parameter penghalus dalam spline ketika terdapat error yang independen dengan varian tidak diketahui. GCV mempunyai kelebihan diantaranya dalam mengitung nilai bersifat sederhana, optimal secara asimtotik, invarian terhadap transformasi dan tidak memerlukan informasi terhadap $\sigma^{2}$. Sholicha, Budiantara, dan Ratna (2018) merumuskan mengenai GCV pada Regresi Nonparametrik Spline truncated untuk memodelkan persentase Unmet Need di Kabupaten Gresik dengan hasil model regresi nonparametrik Spline truncated terbaik yaitu kombinasi titik knot. Puteri (2018) meneliti mengenai harga saham bulanan pada kelompok saham perusahaan penyedia jasa telekomunikasi dimana model terbaik spline yaitu terletak pada orde dua dengan tiga titik knot untuk masing-masing subyek pada data longitudinal.

Menekan nilai AKI hingga mencapai target dari MDGs atau bahkan lebih rendah perlu diperhatikan, yaitu dengan mengetahui faktor-faktor yang berpengaruh terhadap penyebab tingginya nilai AKI. Salah satu penelitian mengenai AKI yaitu penelitian melihat pengaruh AKI terhadap variabel wanita yang menikah pada usia <17 tahun, penolong persalinan oleh non medis, dan komplikasi kebidanan. Setelah dikaji lebih lanjut ternyata variabel wanita yang menikah pada usia $<17$ tahun dan penolong 
persalinan oleh tenaga non-medis memiliki pengaruh langsung dan tidak langsung terhadap AKI (Yasril dan Mahmudah, 2014). Kurniawan (2014) meneliti mengenai determinan kematian ibu jumlah kematian bayi dan jumlah kematian ibu di Provinsi Jawa Timur tahun 2013 dengan menggunakan model regresi binomial negatif bivariat dimana variabel yang diambil dari McCarthy dan Maine.

Salah satu peneliti yang menggunakan regresi nonparametrik Spline mengenai kematian ibu yaitu Arfan (2014) menggunakan pendekatan Spline truncated untuk estimasi kurva regresi nonparametrik pada kasus angka kematian maternal. Penelitian ini menyimpulkan beberapa variabel yang memiliki pengaruh signifikan terhadap kematian ibu yaitu penggunaan tablet Fe1 untuk ibu hamil, ibu hamil yang melaksanakan program $\mathrm{K} 1$, ibu hamil memiliki resiko yang sudah ditangani, perilaku hidup sehat, perempuan yang melakukan perkawinan di bawah umur, dan pendidikan. Berdasarkan penelitian ini, diketahui bahwa scatterplot antara AKI dan masing-masing prediktornya tidak mengikuti pola tertentu sehingga memenuhi asumsi dari regresi nonparametrik.

Dari penelitian yang sudah diuraikan, maka penelitian ini mengkaji pemilihan titik knot dengan menggunakan metode $G C V$ untuk regresi nonparametrik multivariable spline dan memodelkan AKI terbaik di Provinsi Bali.

\section{Metode Penelitian}

\subsection{Regresi Nonparametrik Multivariabel Spline}

Bagian Identifikasi Variabel Diberikan data berpasangan $\left(x_{1 i}, x_{2 i}, \ldots, x_{h i}, y_{i}\right)$ dan hubungan antara variabel $\left(x_{1 i}, x_{2 i}, \ldots, x_{h i}\right)$ dan $y_{i}$ diasumsikan mengikuti model regresi nonparametrik, yang ditunjukkan pada (1) (Eubank, 1999)

$$
y_{i}=f\left(x_{1 i}, x_{2 i}, \ldots, x_{h i}\right)+\varepsilon_{i}, i=1,2, \ldots, n
$$

dengan $y_{i}$ adalah variabel respon, $f$ adalah kurva regresi yang tidak diketahui bentuknya. Jika $f$ didekati dengan fungsi Spline dengan mensubtitusikan (2) ke (1) maka diperoleh model regresi, pada (3).

$$
\begin{aligned}
& y_{i}=f_{1}\left(x_{1 i}\right)+f_{2}\left(x_{2 i}\right)+\ldots+f_{h}\left(x_{h i}\right)+\varepsilon_{i} \\
&=\sum_{j=1}^{h} f_{j}\left(x_{j i}\right)+\varepsilon_{i}, i=1,2, \ldots, n \\
& \text { Dengan } f_{j}\left(x_{j i}\right)=\sum_{u=0}^{p} \beta_{u j} x_{j i}^{u}+\sum_{k=1}^{r} \beta_{(p+k) j}\left(x_{j i}-K_{k j}\right)_{+}^{p}, j=1,2, \ldots, h \\
& y_{i}=\sum_{u=0}^{p} \beta_{u j} x_{j i}^{u}+\sum_{k=1}^{r} \beta_{(p+k) j}\left(x_{j i}-K_{k j}\right)_{+}^{p}+\varepsilon_{i}, i=1,2, \ldots, n .
\end{aligned}
$$


Nilai $K_{k j}$ merupakan titik-titik knot. Nilai $p$ merupakan derajat dari Spline. Kurva Spline polinomial derajat satu disebut fungsi Spline linier, derajat dua disebut fungsi Spline kuadratik, dan derajat tiga disebut fungsi Spline kubik.

Fungsi (3) $\left(x_{j i}-K_{k j}\right)_{+}^{p}$ merupakan fungsi truncated (potongan) sebagai berikut:

$$
\left(x_{j i}-K_{k j}\right)_{+}^{p}=\left\{\begin{array}{cl}
\left(x_{j i}-K_{k j}\right)^{p}, & x_{j i} \geq K_{k j} \\
0 & , x_{j i}<K_{k j}
\end{array} .\right.
$$

\subsection{Metode Pemilihan Titik Knot Optimal}

Salah satu hal penting dalam Spline truncated adalah memilih titik knot optimal untuk sekumpulan data, dalam mencari estimator Spline truncated yang paling sesuai. Untuk memperoleh Spline truncated terbaik bergantung pada pemilihan titik-titik knot. Dalam Spline truncated. Pemilihan titik knot optimal dalam regresi Spline truncated pada umumnya didasarkan pada metode Generalized Cross-Validation (GCV). Secara umum GCV didefinisikan (4) (Wu \&Zhang, 2006).

$$
\operatorname{GCV}\left(K_{1}, K_{2}, \ldots, K_{r}\right)=\frac{\operatorname{MSE}\left(K_{1}, K_{2}, \ldots, K_{r}\right)}{\left\{n^{-1} \operatorname{trace}\left[\mathbf{I}-\mathbf{A}\left(K_{1}, K_{2}, \ldots, K_{r}\right)\right]\right\}^{2}}
$$

dengan:

$\operatorname{MSE}\left(K_{1}, K_{2}, \ldots, K_{r}\right)=\frac{1}{n} \sum_{i=1}^{n}\left(y_{i}-\hat{y}_{i}\right)^{2}$

dengan $\mathbf{A}\left(K_{1}, K_{2}, \ldots, K_{r}\right)=\mathbf{X}\left(\mathbf{X}^{\prime} \mathbf{X}\right)^{-1} \mathbf{X}^{\prime}$, dan $\mathbf{I}$ matriks identitas.

\subsection{Jenis dan Sumber Data}

Penelitian ini menggunakan data sekunder yang diperoleh dari Dinas Kesehatan (Dinkes) Provinsi Bali dan data dari Survei Sosial Ekonomi Nasional (SUSENAS) Provinsi Bali, meliputi 57 kecamatan yang terletak di Provinsi Bali. Data memuat informasi tentang Angka Kematian Ibu (AKI) dan faktor-faktor yang mempengaruhi AKI, dimana akan digunakan sebagai variabel penelitian. Adapun gambaran umum variabel penelitian yang digunakan sebagai berikut:

1. Variabel respon yaitu Angka Kematian Ibu (AKI) ( $\left.\mathrm{y}_{1}\right)$

2. Variabel bebasnya yaitu terdiri dari: persentase persalinan oleh tenaga medis $\left(\mathrm{x}_{1}\right)$, persentase ibu hamil mengkonsumsi Tablet $\mathrm{Fe} 1\left(\mathrm{x}_{2}\right)$, persentase ibu hamil melakukan program K1 ( $\left.\mathrm{x}_{3}\right)$, persentase ibu hamil melakukan program $\mathrm{K} 4\left(\mathrm{x}_{4}\right)$.

Langkah-langkah penelitian dibuat dalam bentuk diagram alir seperti Gambar 1. 


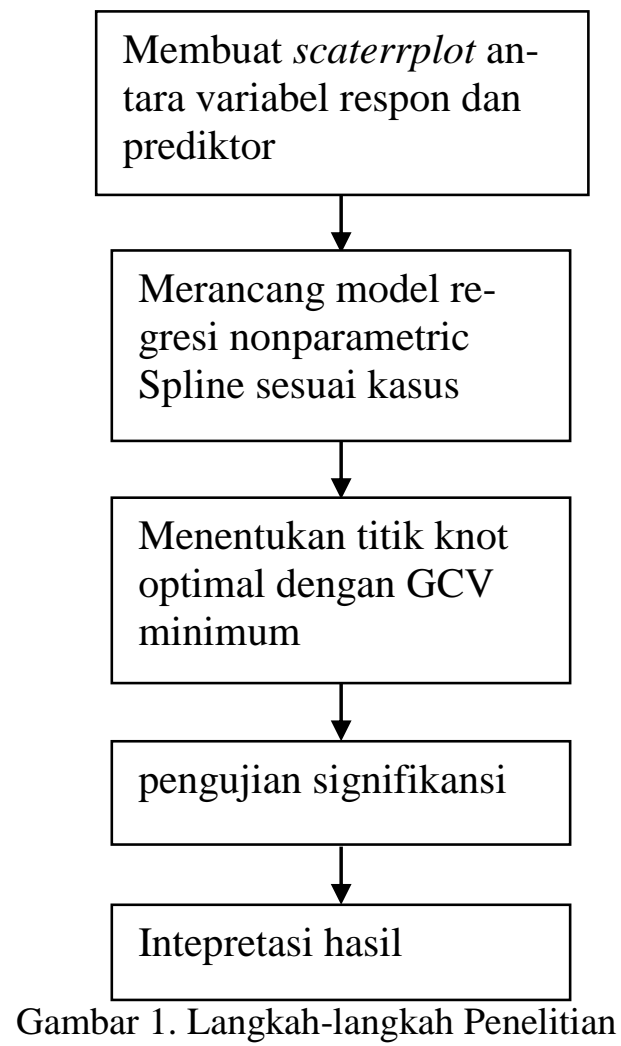

\section{Hasil dan Pembahasan}

Sebelum dianalisis menggunakan analisis regresi Spline terlebih dahulu diselidiki pola hubungan antara masing-masing variabel prediktor dengan variabel respon dengan menggunkan scatter plot. Plot ini dilakukan bertujuan untuk mengetahui deteksi awal pola data. Hasil dari scatter plot dapat dilihat pada Gambar 2.

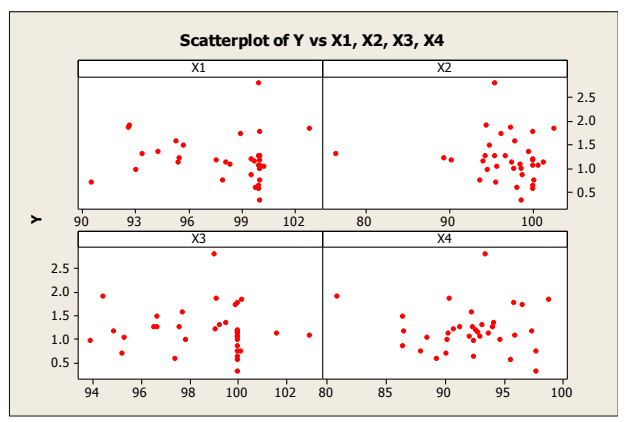

Gambar 2.Scatter Plot Variabel Respon $y_{1}$ dengan Variabel Prediktor $x_{1}, x_{2}, x_{3}, x_{4}$ 
Pada Gambar 2, dapat dilihat bahwa AKI dengan variabel $x_{1}, x_{2}, x_{3}$, dan $x_{4}$ tidak mengikuti pola tertentu. Jadi pola hubungan antara masing-masing variabel prediktor dengan variabel respon menggunakan pendekatan nonparametrik dan pemodelannya menggunakan regresi nonparametrik.

\subsection{Pemilihan Titik Knot Optimal Linier Satu Knot}

Pemilihan titik knot optimal pada regresi Spline linier satu titik knot pada AKI di Provinsi Bali dengan empat variabel prediktornya. Model regresi nonparametrik Spline linier yang terbaik diperolah dari titik-titik knot yang optimum yaitu GCV terkecil, yang ditunjukkan oleh Tabel 1.

Tabel 1. Nilai GCV untuk Spline Linier Satu Knot

\begin{tabular}{|c|c|c|c|c|}
\hline \multicolumn{4}{|c|}{ Knot } & \multirow[b]{2}{*}{ Nilai GCV } \\
\hline $\mathrm{X}_{1}$ & $\mathrm{x}_{2}$ & $\mathrm{x}_{3}$ & $\mathrm{X} 4$ & \\
\hline 92,03 & 79,64 & 95,03 & 83,01 & 0,38338 \\
\hline 93,04 & 81,77 & 95,76 & 84,48 & 0,38244 \\
\hline 92,28 & 80,18 & 95,21 & 83,38 & 0,37928 \\
\hline 92,53 & 80,71 & 95,40 & 83,75 & 0,37626 \\
\hline 92,79 & 81,24 & 95,58 & 84,11 & $\mathbf{0 , 3 7 3 3 1}$ \\
\hline 91,78 & 79,11 & 94,84 & 82,65 & 0,38546 \\
\hline 91,53 & 78,58 & 94,66 & 82,28 & 0,38621 \\
\hline 93,29 & 82,30 & 95,95 & 84,85 & 0,38699 \\
\hline 93,54 & 82,84 & 96,13 & 85,22 & 0,38749 \\
\hline 91,28 & 78,05 & 94,47 & 81,91 & 0,39476 \\
\hline
\end{tabular}

Berdasarkan Tabel 1, GCV paling kecil yaitu sebesar 0.37331 dengan titik knot optimal dapat dilihat pada Tabel 1, dengan nilai sebagai berikut:

$\mathrm{x}_{1}: K_{1}=92,79, \mathrm{x}_{2}: K_{2}=81,24, \mathrm{x}_{3}: K_{3}=95,58, \mathrm{x}_{4}: K_{4}=84,11$.

\subsection{Pemilihan Titik Knot Optimal Linier Dua Knot}

Berikut ini adalah estimasi model regresi nonparametrik Spline linier dengan dua titik knot pada kasus AKI, yang ditunjukkan oleh Tabel 2. 
Tabel 2. Nilai GCV pada Spline Linier Dua Knot

\begin{tabular}{|c|c|c|c|c|}
\hline \multicolumn{4}{|c|}{ Knot } & \multirow[b]{2}{*}{ GCV } \\
\hline $\mathrm{X}_{1}$ & $\mathrm{X}_{2}$ & $\mathrm{x}_{3}$ & $\mathrm{X}_{4}$ & \\
\hline 97,80 & 91,89 & 99,27 & 91,46 & 0,33765 \\
\hline 98,05 & 92,42 & 99,45 & 91,82 & \\
\hline 97,55 & 91,35 & 99,09 & 91,09 & 0,31712 \\
\hline 98,30 & 92,95 & 99,64 & 92,19 & \\
\hline 97,30 & 90,82 & 98,90 & 90,72 & 0,31095 \\
\hline 98,05 & 92,42 & 99,45 & 91,82 & \\
\hline 97,30 & 90,82 & 98,90 & 90,72 & 0,29523 \\
\hline 98,30 & 92,95 & 99,64 & 92,19 & \\
\hline 97,55 & 91,35 & 99,09 & 91,09 & 0,28500 \\
\hline 98,05 & 92,42 & 99,45 & 91,82 & \\
\hline 97,05 & 90,29 & 98,72 & 90,36 & 0,33854 \\
\hline 98,30 & 92,95 & 99,64 & 92,19 & \\
\hline 97,55 & 91,35 & 99,09 & 91,09 & 0,35996 \\
\hline 97,80 & 91,89 & 99,27 & 91,46 & \\
\hline 90,78 & 76,98 & 94,10 & 81,18 & 0,37954 \\
\hline 91,03 & 77,51 & 94,29 & 81,54 & \\
\hline 90,78 & 76,98 & 94,10 & 81,18 & 0,38369 \\
\hline 91,53 & 78,58 & 94,66 & 82,28 & \\
\hline 97,30 & 90,82 & 98,90 & 90,72 & 0,38477 \\
\hline
\end{tabular}

Berdasarkan Tabel 2, terlihat bahwa nilai GCV minimum adalah 0,28500, dengan titik knot optimal dapat dilihat pada Tabel 2 adalah:

$\mathrm{x}_{1}:\left(K_{1}=97,55 ; K_{2}=91,35\right), \mathrm{x}_{2}:\left(K_{3}=99,09 ; K_{4}=91,09\right)$,

$\mathrm{x}_{3}:\left(K_{5}=98,05 ; K_{6}=92,42\right), \mathrm{x}_{4}:\left(K_{7}=99,45 ; K_{8}=91,82\right)$,

\subsection{Pemilihan Titik Knot Optimal Linier Tiga Knot}

Setelah diperoleh dua titik knot, estimasi model regresi nonparametrik Spline linier tiga knot Tabel 3. 
Tabel 3. Nilai GCV pada Spline Linier Tiga Knot

\begin{tabular}{|c|c|c|c|c|}
\hline \multicolumn{4}{|c|}{ Knot } & \multirow{2}{*}{ Nilai GCV } \\
\hline $\mathrm{X}_{1}$ & $\mathrm{X}_{2}$ & $\mathrm{X}_{3}$ & $\mathrm{X}_{4}$ & \\
\hline 93,29 & 82,30 & 95,95 & 84,85 & \\
\hline 97,80 & 91,89 & 99,27 & 91,46 & 0,09696 \\
\hline 98,05 & 92,42 & 99,45 & 91,82 & \\
\hline 92,79 & 81,24 & 95,58 & 84,11 & \\
\hline 97,55 & 91,35 & 99,09 & 91,09 & 0,09424 \\
\hline 98,55 & 93,48 & 99,82 & 92,56 & \\
\hline 93,04 & 81,77 & 95,76 & 84,48 & \\
\hline 97,55 & 91,35 & 99,09 & 91,09 & 0,08466 \\
\hline 98,30 & 92,95 & 99,64 & 92,19 & \\
\hline 93,04 & 81,77 & 95,76 & 84,48 & \\
\hline 97,30 & 90,82 & 98,90 & 90,72 & 0,08299 \\
\hline 98,30 & 92,95 & 99,64 & 92,19 & \\
\hline 92,79 & 81,24 & $\mathbf{9 5 , 5 8}$ & 84,11 & \\
\hline 97,80 & 91,89 & 99,27 & 91,46 & $\mathbf{0 , 0 7 7 2 2}$ \\
\hline 98,30 & 92,95 & 99,64 & 92,19 & \\
\hline 95,29 & 86,56 & 97,43 & 87,79 & \\
\hline 97,30 & 90,82 & 98,90 & 90,72 & 0,09942 \\
\hline 98,05 & 92,42 & 99,45 & 91,82 & \\
\hline 95,29 & 86,56 & 97,43 & 87,79 & \\
\hline 97,30 & 90,82 & 98,90 & 90,72 & 0,10214 \\
\hline 97,80 & 91,89 & 99,27 & 91,46 & \\
\hline 93,04 & 81,77 & 95,76 & 84,48 & \\
\hline 97,80 & 91,89 & 99,27 & 91,46 & 0,10240 \\
\hline 98,05 & 92,42 & 99,45 & 91,82 & \\
\hline 93,04 & 81,77 & 95,76 & 84,48 & \\
\hline 97,05 & 90,29 & 98,72 & 90,36 & 0,10566 \\
\hline 98,30 & 92,95 & 99,64 & 92,19 & \\
\hline 93,04 & 81,77 & 95,76 & 84,48 & \\
\hline 97,30 & 90,82 & 98,90 & 90,72 & 0,11028 \\
\hline 98,05 & 92,42 & 99,45 & 91,82 & \\
\hline
\end{tabular}

Berdasarkan Tabel 3, terlihat bahwa GCV minimum sebesar 0,07722. Berikut ini adalah nilai titik knot optimum untuk tiga titik knot pada masing-masing variabel komponen nonparametrik, sebagai berikut:

$$
\begin{aligned}
& \mathrm{x}_{1}:\left(K_{1}=92,79 ; K_{2}=81,24 ; K_{3}=95,58\right), \\
& \mathrm{x}_{2}:\left(K_{4}=84,11 ; K_{5}=97,80 ; K_{6}=91,89\right),
\end{aligned}
$$




$$
\begin{aligned}
& \mathrm{x}_{3}:\left(K_{7}=99,27 ; K_{8}=91,46 ; K_{9}=98,30\right), \\
& \mathrm{x}_{4}:\left(K_{10}=92,95 ; K_{11}=99,64 ; K_{12}=92,19\right),
\end{aligned}
$$

Berdasarkan hasil GCV satu knot, dua knot, tiga knot, maka yang digunakan dalam pemodelan adalah knot dengan nilai GCV terkecil dari semua knot yang dihasilkan. Dapat dilihat pada Tabel 4 perbandingan nilai GCV minimum sebagai berikut:

Tabel 4. Perbandingan Nilai GCV minimum dari titik knot

\begin{tabular}{|l|l|}
\hline Titik Knot & Nilai GCV Minimum \\
\hline Satu Titik Knot & 0,37331 \\
\hline Dua Titik Knot & 0,28500 \\
\hline Tiga Titik Knot & 0,07722 \\
\hline
\end{tabular}

Pada Tabel 4 diperoleh nilai GCV terkecil terletak pada tiga titik knot yaitu sebesar 0,07722 hasil ini selanjutnya akan digunakan dalam pemodelan AKI di Provinsi Bali.

\subsection{Pemodelan AKI Menggunakan Knot Optimal}

Pemodelan AKI di Provinsi Bali dengan menggunakan tiga titik knot berdasarkan pemilihan titik knot optimal yang telah dilakukan, dengan model yang terbentuk menggunakan tiga titik knot sebagai berikut

$$
\begin{aligned}
\hat{y}= & 0,08+3,38 x_{1}-3,37\left(x_{1}-92,79\right)_{+}-2,55\left(x_{1}-97,80\right)_{+}+2,90\left(x_{1}-98,30\right)_{+}-3,87 x_{2}+6,79\left(x_{2}-81,24\right)_{+} \\
& -9,41\left(x_{2}-91,89\right)_{+}+6,41\left(x_{2}-92,95\right)_{+}+1,45 x_{3}-1,53\left(x_{3}-95,58\right)_{+}+0,46\left(x_{3}-99,27\right)_{+} \\
& +0,01\left(x_{3}-99,64\right)_{+}-1,33 x_{4}+1,60\left(x_{4}-84,11\right)_{+}-0,17\left(x_{4}-91,46\right)_{+}-0,21\left(x_{4}-92.19\right)_{+}
\end{aligned}
$$

Hasil lain yang diperoleh bahwa dengan tiga titik knot ini menghasilkan $\mathrm{R}^{2}$ sebesar 98,59 persen, yang berarti model ini dapat menjelaskan AKI sebesar 98,59 persen.

\subsection{Pengujian Signifikansi Parameter}

\subsubsection{Uji Serentak}

Uji hipotesis serentak untuk parameter model diberikan oleh:

$$
\begin{aligned}
& H_{0}: \beta_{11}=\beta_{21}=\cdots=\beta_{(p+r) h}=0 \\
& H_{1}: \text { minimal ada satu } \beta_{u j} \neq 0, u=1,2, \ldots,(p+r), \text { dan } j=1,2, \ldots, h .
\end{aligned}
$$

Hasil uji estimasi parameter secara serentak dapat dilihat dalam Tabel 5.

Tabel 5. Analysis of Variance (ANOVA)

\begin{tabular}{|l|l|l|l|l|}
\hline SumberVariansi & df & SS & MS & Fhit \\
\hline Regresi & 53 & 7,589 & 0,143 & 3,97 \\
\hline Error & 3 & 0,108 & 0,036 & \\
\hline Total & 56 & 7,697 & - & \\
\hline
\end{tabular}


Tabel 5, diperoleh nilai $F_{h i t}=3,97>F_{\text {tabel }}=3,820$, sehingga dalam hal ini dapat diambil keputusan bahwa $\mathrm{H}_{0}$ ditolak. Berdasarkan keputusan tersebut dapat diambil kesimpulan minimal terdapat satu variabel yang memberikan pengaruh signifikan terhadap AKI, yang dilanjutkan dengan pengujian signifikansi parameter secara individu.

\subsubsection{Uji Individu}

Pengujian secara individu dilakukan untuk mengetahui signifikasi parameter apakah ketujuh parameter dalam persamaan regresi yang dihasilkan memiliki pengaruh signifikan terhadap AKI atau tidak. Hipotesis pada uji $\mathrm{t}$

$$
\begin{aligned}
& H_{0}: \hat{\beta}_{u j}=0 \\
& H_{1}: \hat{\beta}_{u j} \neq 0
\end{aligned}
$$

Hasil pengujian signifikansi parameter secara individu diketahui bahwa terdapat beberapa parameter yang tidak signifikan. Apabila $\left|t_{\text {hit }}\right|>t_{0,025 ; 3}=2,44$, maka variabel prediktor memberikan pengaruh terhadap AKI, dari 17 parameter terdapat dua parameter yang tidak signifikan terhadap AKI. Sementara itu estimasi parameter yang signifikan terhadap AKI merupakan parameter dari empat variabel yang diduga mempengaruhi AKI. Meskipun terdapat dua parameter yang tidak signifikan, namun secara keseluruhan keempat variabel $\mathrm{x}_{1}, \mathrm{x}_{2}, \mathrm{x}_{3}$, dan $\mathrm{x}_{4}$ memberikan pengaruh terhadap AKI.

\subsection{Pengujian Asumsi Error}

\subsubsection{Uji Identik}

Asumsi error identik digunakan uji Glejser yang berfungsi untuk mengetahui apakah varians dari error identik atau tidak. Hipotesis untuk uji Glesjer:

Ho: error identik

$\mathrm{H}_{1}$ : error tidak identik

Berikut adalah hasil uji Glesjer, pada Tabel 6.

Tabel 6.ANOVA dari Uji Glejser

\begin{tabular}{|l|l|l|l|l|}
\hline Sumber Variansi & df & SS & MS & Fhit \\
\hline Regresi & 53 & 0,051 & 0,002 & 0,990 \\
\hline Error & 3 & 0,011 & 0,002 & \\
\hline Total & 56 & 0,063 & - & \\
\hline
\end{tabular}

Berdasarkan Tabel 6, bahwa nilai statistik uji $\mathrm{F}_{\text {hit }}=0,990<\mathrm{F}_{\text {tabel }}=3,820$, sehingga dapat disimpulkan bahwa tidak terdapat kasus heteroskedastisitas dan dapat dikatakan bahwa error telah memenuhi asumsi identik. 


\subsubsection{Uji Independen}

Salah satu cara mendeteksi adanya independensi pada error yaitu dengan dengan perhitungan nilai durbin Watson nilai $\mathrm{d}_{\text {hitung }}=2,419>\mathrm{d}_{\mathrm{U}}=1,034$. Sehingga gagal tolak Ho yang dapat disimpulkan bahwa asumsi error independen telah terpenuhi.

\subsubsection{Uji Distribusi Normal}

Pengujian asumsi error berdistribusi normal dilakukan menggunakan uji Kolmogorov-Smirnov. Berdasarkan Tabel Kolmogorov-Smirnov didapatkan nilai $D_{0,05 ; 35}$ sebesar 0,224. Sementara itu statistik uji D yaitu sebesar 0,178. Keputusan yang diperoleh yaitu gagal tolak $\mathrm{H}_{0}$ karena $D<D_{0,05 ; 35}$. Berdasarkan keputusan tersebut dapat disimpulkan bahwa asumsi error berdistribusi normal telah terpenuhi.

Semua asumsi error yaitu error identik, independen dan berdistribusi normal telah terpenuhi. Oleh karena itu, model regresi nonparametrik Spline cocok untuk menggambarkan hubungan variabel prediktor terhadap AKI

\section{Kesimpulan dan Saran}

\subsection{Kesimpulan}

Model yang terbaik yang dapat menggambarkan AKI di Provinsi Bali yaitu dengan model Spline linier tiga titik knot. Model yang terbentuk yaitu:

$$
\begin{aligned}
\hat{y}= & 0,08+3,38 x_{1}-3,37\left(x_{1}-92,79\right)_{+}-2,55\left(x_{1}-97,80\right)_{+}+2,90\left(x_{1}-98,30\right)_{+}-3,87 x_{2}+6,79\left(x_{2}-81,24\right)_{+} \\
& -9,41\left(x_{2}-91,89\right)_{+}+6,41\left(x_{2}-92,95\right)_{+}+1,45 x_{3}-1,53\left(x_{3}-95,58\right)_{+}+0,46\left(x_{3}-99,27\right)_{+} \\
& +0,01\left(x_{3}-99,64\right)_{+}-1,33 x_{4}+1,60\left(x_{4}-84,11\right)_{+}-0,17\left(x_{4}-91,46\right)_{+}-0,21\left(x_{4}-92.19\right)_{+}
\end{aligned}
$$

Variabel yang berpengaruh terhadap AKI ialah persentase persalinan oleh tenaga medis $\left(\mathrm{x}_{1}\right)$, persentase ibu hamil mengkonsumsi Tablet Fe1 $\left(\mathrm{x}_{2}\right)$, persentase ibu hamil melakukan program $\mathrm{K} 1\left(\mathrm{x}_{3}\right)$, persentase ibu hamil melakukan program $\mathrm{K} 4\left(\mathrm{x}_{4}\right)$. Dengan, nilai GCV: 0,07722 dan nilai MSE sebesar: 0,018.

\subsection{Saran}

Penelitian ini terbatas pada penggunaan regresi Spline linier. Saran yang dapat diberikan dalam penelitian selanjutnya adalah dapat dikembangkan dengan menggunakan regresi Spline kuadratik dan kubik. 


\section{Ucapan Terima Kasih}

Penulis mengucapkan terima kasih kepada ITB STIKOM Bali yang telah memberi dukungan financial terhadap penelitian ini dengan judul Pemilihan Titik Knot Optimal Model Spline Truncated dalam Regresi Nonparametrik Multivariabel dengan GCV

\section{Daftar Pustaka}

Amato, U., Antoniadis, A., \& De Feis,I. (2002). Fourier Series Approximation of Separable Models.Journal of Computation and Applied Mathematics, Vol 146, Hal. 459479.

Arfan, N. (2014), Pendekatan Spline untuk Estimasi Kurva Regresi Nonparametrik (Studi Kasus Pada Data Angka Kematian Maternal di Jawa Timur), Skripsi, Jurusan Statistika, FMIPA, Institut Teknologi Sepuluh Nopember (ITS), Surabaya.

Budiantara, I. N. (2006). Model Spline Dengan Knots Optimal.Jurnal ilmu dasar, Vol. 7, Hal. 77-85.

Budiantara, I.N., Suryadi, F., Otok, B.W. \&Guritno, S. (2006). Pemodelan B-Spline dan MARS Pada Nilai Ujian Masuk terhadap IPK Mahasiswa Jurusan Disain Komunikasi Visual UK. Petra Surabaya. Jurnal Teknik Industri, 8:1-13.2006.

Budiantara, I. N. (2009). Spline dalam Regresi Nonparametrik dan Semiparametrik: Sebuah Pemodelan Statistika Masa Kini dan Masa Mendatang. ITS Press, Institut Teknologi Sepuluh Nopember Surabaya.

Budiantara, I Nyoman. (2016). Kumpulan: Makalah-Makalah Yang DipublikasikanDalam Jurnal Dan Seminar Jilid 1. Institut Teknologi Sepuluh Nopember(ITS) Surabaya.

Eubank, R. L. 1999. Nonparametric Regression and Spline Smoothing (2nd ed.). New York: Marcel Dekker.

Fan, J. \& Jiang, J. (2005). Nonparametric Inferences for Additive Models.Journal of The Statistical association, Vol. 100, Hal. 890-907.

Hu, Z., Wang, N., \& Carroll, R.J. (2004). Profile Kernel Versus Backfitting In The Partially Linier Models For Longitudinal Or Clustered Data. Journal Biometrika, Vol. 91, Hal. 251-262.

Kurniawan, U. (2014). Penaksiran dan Pengujian Hipotesis Parameter Model Regresi Binomial Negatif Bivariat, Tesis, Jurusan Statistika, FMIPA, Institut Teknologi Sepuluh Nopember (ITS), Surabaya.

Puteri, N. W. (2018). Pemodelan Regresi Spline Truncated Untuk Data Longitudinal (Studi Kasus : Harga Saham Bulanan pada Kelompok Saham Perusahaan Penyedia Jasa Telekomunikasi Periode Januari 2009-Desember 2016). Skripsi, Jurusan Statistika,FMIPA, Universitas Islam Indonesia Yogyakarta 2018.

Sholicha, C. N., Budiantara, I. N., \&Ratna, M. (2018). Regresi Nonparametrik Spline Truncated untuk Memodelkan Persentase Unmet Need di Kabupaten Gresik. Jurnal Sains Dan Seni Its, Vol. 7, No. 2, 2337-3520 (2301-928X Print).

Wu, H. \& Zhang, J. T. (2006). Nonparametric Regression Methods for Longitudinal Data Analysis. New York: John Wiley and Sons, Inc. 
Yasril, A. I. \& Mahmudah. (2014). Analisis Jalur Faktor Angka Kematian Ibu Di Provinsi Jawa Timur Tahun 2014. Jurnal Biometrika dan Kependudukan, Vol. 7, No. 2 Desember 2018: 149-159. 